\title{
THE MAIN PORTAL OF THE CATHEDRAL OF MONREALE: FIRST GEOMETRIC ANALYSIS AND INTERPRETIVE ASSESSMENT OF ARCHITECTURAL FEATURES
}

\author{
M. Lo Brutto ${ }^{\text {a, } * \text {, G. Dardanelli }}{ }^{\text {a }}$, D. Ebolese ${ }^{\text {a }}$, G. Milazzo ${ }^{\text {b }}$, C. Pipitone ${ }^{\text {a }}$, R. Sciortino ${ }^{\text {a }}$ \\ ${ }^{a}$ Dept. of Civil, Environmental, Aerospace, Materials Engineering (DICAM), University of Palermo, Italy \\ (mauro.lobrutto, gino.dardanelli, donatella.ebolese, claudia.pipitone02, rosanna.sciortino)@unipa.it \\ ${ }^{\mathrm{b}}$ Milazzo Restauri S.r.1, Palermo, Italy \\ giu.milazzo@gmail.com
}

KEY WORDS: Cultural Heritage, Restoration, Photogrammetry, 3D survey, 3D Modelling, Monumental Portal.

\begin{abstract}
:
Nowadays, 3D documentation of architectural assets is becoming a demanding task for the valorisation of Cultural Heritage especially after a restoration project. The 3D documentation can be used for detailed analysis of specific elements, for monitoring the state of conservation and for valorisation actions. The paper describes the results of the 3D close-range photogrammetry survey of the main portal of the Cathedral of Monreale (Palermo, Italy). The Cathedral is one the most important monumental complexes in Sicily that, for its high historical and artistic importance has been inscribed on UNESCO's World Heritage List since 2015. The main portal of the Cathedral has been recently restored. The restoration work has given the opportunity to evidence small details of the sculptural decorations and to carry out new interpretative analysis of the bas-reliefs.

The main purpose of the work is to obtain a detailed 3D model and a high-resolution ortophoto of the entire portal and of some architectural details. The study was used to evaluate the most appropriate technical solutions for the $3 \mathrm{D}$ survey and to define the most suitable parameters for image acquisition and data processing.
\end{abstract}

\section{INTRODUCTION}

The 3D documentation of architectural parts of great monumental complexes allows to increase the understanding of the monument and to bring out many meaningful details (Martínez et al., 2013).

The study of individual architectural elements is a very important step for the knowledge of monumental complexes especially when they are richly decorated with sculptures, mosaics, bas-reliefs, paintings (Fassi et al., 2011).

Nowadays, 3D documentation of architectural assets is becoming a demanding task for the valorisation of Cultural Heritage especially after a restoration project, such as for deformation or degradation monitoring purposes.

Among the most important monumental complexes in Sicily, the Cathedral of Monreale (Palermo, Italy) is one of the most known for its artistic and historical value. The Cathedral and the adjacent Benedictine Cloister constitute a monumental complex that for its high historical-artistic importance has been inscribed on UNESCO's World Heritage List since 2015.

Among all external architectural elements, the main portal of the Cathedral of Monreale is one of the most important of the whole complex; this portal has been recently restored. For this reason, a first detailed 3D survey of the main portal was planned to obtain 3D data useful for documentation, geometric analysis and interpretive assessment.

The work was carried out by an accurate 3D close-range photogrammetric survey. The survey has been aimed to produce a detailed 3D model and a high-resolution ortophoto that allows to point out and to manage information about many elements of the surveyed object. These products allow to provide a first metric and reliable documentation of the portal and a deep analysis of the artistic sculptures of this important architectural element.

The paper describes in detail the study carried out for the planning of the photogrammetry survey and the results of the first tests.

\section{THE MAIN PORTAL OF THE CATHEDRAL OF MONREALE}

The Cathedral of Monreale is one of the main monuments of the Arab-Norman period in Sicily (Figure 1), known for its precious inner decoration made of Byzantine mosaics. The construction of Cathedral was ordered by King William II around 1174 and was finished in 1267 . The dimensions of the Cathedral are enormous: 102 meters long and 40 meters wide. The Cathedral has a Latin cross plant with a transept which is a continuation of the aisles. The aisles are divided by ancient columns that support lancet arches; each nave ends with a semicircular apse.

Most of the interior of the Cathedral is covered with Byzantine mosaics with a gold background, executed between the XII and mid-XIII century. The mosaics, imposing by extension and stylistic quality, mainly represent the Old and New Testament stories and various biblical episodes.

After its construction, the Cathedral had some significant transformations but the liturgical arrangement still remains as in origin. In particular, between 1547 and 1569 along the northern side of the Cathedral was built the ancient portico, designed by Giovanni Domenico Gagini and Fazio Gagini. The portico was built in the Renaissance style, covered with a cross vault and

* Corresponding author 
open to the outside with eleven semi-circular arches resting on Corinthian columns. In correspondence with the central arch, it is located the lateral portal, whose bronze doors were made around 1185 by Barisano da Trani. In 1770 it was added the portico on the main façade (Figure 2) built in the Baroque style. The portico on the main façade is constituted by three semicircular arches resting on Tuscan columns; inside the portico, there is the main portal of the Cathedral.

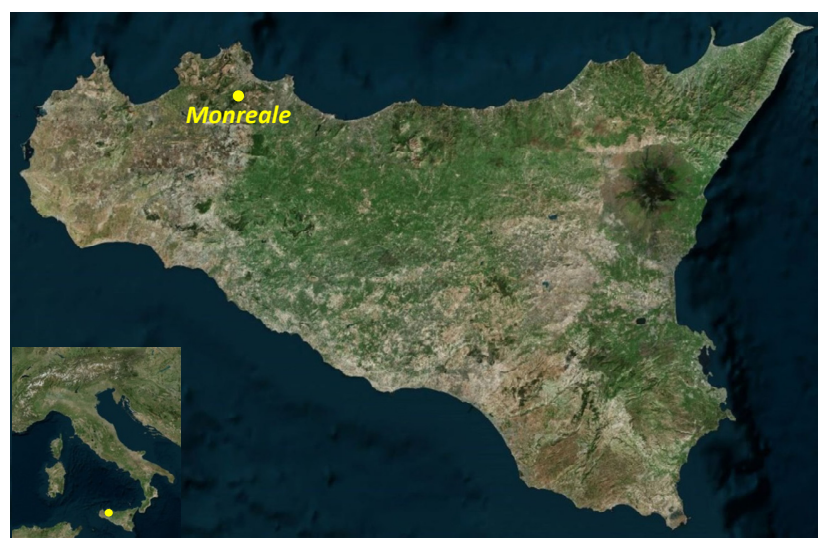

Figure 1. Location of the Cathedral of Monreale

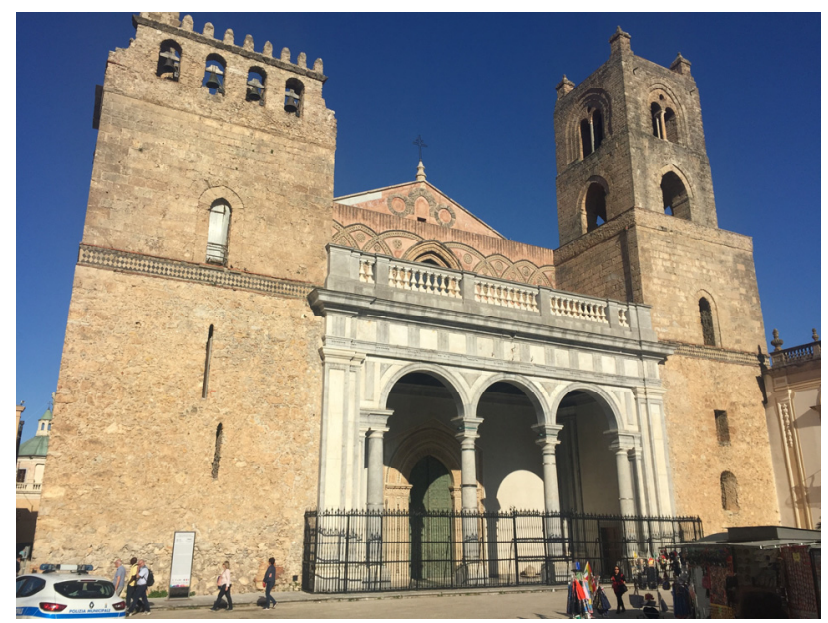

Figure 2. Main façade of Cathedral of Monreale

The main portal is one of the most important external architectural elements of the whole complex. It is known as the "Portal of the Paradise" and it is constituted of a bronze door ("West Door"), two pilasters and an archivolt with a pointed arch (Figure 3). The main portal is approximately 8 meters large and 10 meters high. Bonanno da Pisa made the bronze main door around 1186. It is substantially the greatest bronze door in existence nowadays cast and signed by Bonanno da Pisa; in fact, the inscription states "ANNO D(OMI)NI M.C.L.XXXVI I(N)DICTIO(NE) III BONANUS CIVIS PISANUS ME FECIT",

The iconographic scheme of the bronze door shows 46 scenes of the Old and New Testament; the scenes are divided into different orders with a precise sequence that starts from the Old Testament scenes, in the lower parts of the door, to the scenes of the Christ and the Virgin in heavenly glory in the highest parts of the door (White, 1998). The bronze elements are rested on a wooden base and each panel was nailed to the wood with rosette-tipped nails. The bronze door was manufactured in Pisa and assembled in Monreale. It is likely that there were some mistakes in the measurement of the door because it resulted too narrow for the opening that it was to fill. In fact, a stylistically different central beam was added to mask the central gap. Moreover, it was clearly designed for a rectangular doorway, like that of the Porta di S. Ranieri in Pisa, because it was wholly unrelated to the arched form of the opening. As a result, enthroned figures of the Christ and of the Virgin at the top are masked when the door is closed. Another error occurs at the base of the door, where the right-hand lion is incorrectly oriented within its rectangular frame (Fossi, 2008).

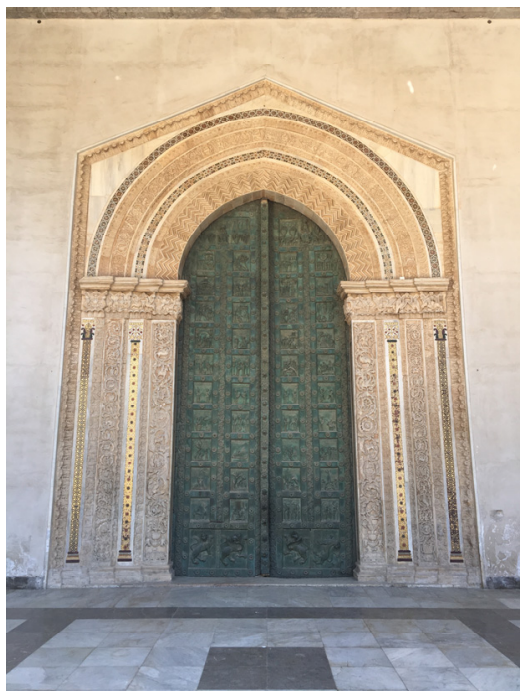

Figure 3. The main portal of the Cathedral of Monreale

The pilasters of the main portal are decorated with mosaics and bas-reliefs regularly alternated that subdivide them into four false columns. The bas-reliefs form an articulated decoration rich of symbolic meanings related to the "fall of the man" and his salvation by means the Christ. Four capitals, sculptured with zoomorphic and anthropomorphic figures, are placed in the top of pilasters of the portal; over them, it is based a lintel with a carved frame. The first arch, the inner, is decorated with a chevron decoration, while the second and the fourth have a mosaic decoration based on the pattern of the eight-pointed star. The third arch has a bas-relief frieze with leaves swirls lived by animals and human figures (Kröning, 1965).

\section{THE RESTORATION WORK}

In the last year, a restoration treatment has been carried out to improve the state of conservation of the marble frame of the bronze door. Before the conservation treatment, the marble, that is the constitute material of the monumental portal, was in a critical and heavy state of conservation for the great extension of the areas involved in the degradation phenomena (Figure 4 and Figure 5). The main causes of the observed decay were due to the previous restoration treatments and to a not efficient water disposal system.

Thanks to an approach oriented to respect the original matter of the work of art, each conservative activity has been aimed to preserve it. A diagnostic survey was carried out to investigate the constitutive materials, the degradation processes and the restoration material used in previous time. Based on the data obtained by the diagnostic, it has been possible to plan the suitable conservative actions that have allowed enhancing the "reading" of the work. 


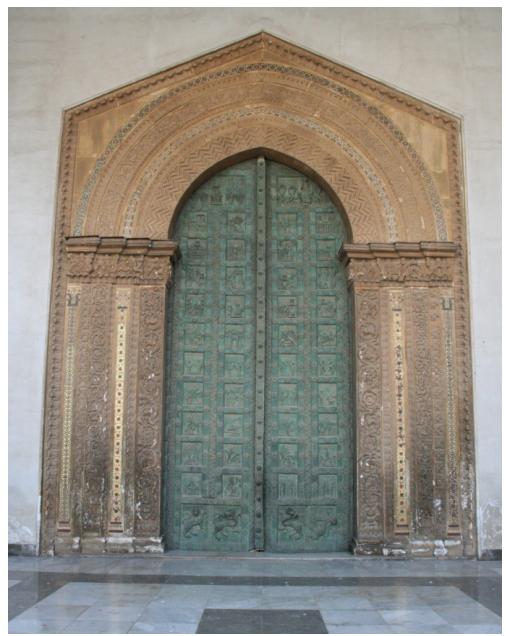

Figure 4. The main portal of the Cathedral of Monreale before the restoration

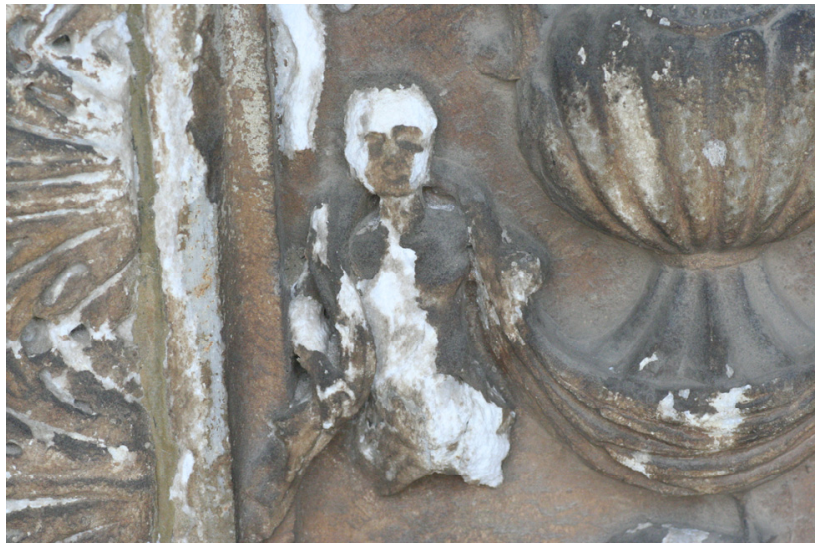

Figure 5. A detail of the bas-relief in right pilaster before the restoration

One of the most complex measures of the restoration has been the cleaning for the removal of the brown synthetic covering and dark deposits from the surface. For this purpose, it has been carried out a selective methodology that it was able to clean the marble, mistaken until then with a local stone, discovering the original colour of the portal. Moreover, the consolidation treatment, provided with a product highly chemically related to the stone, has been the main important treatment to restore the marble and its cohesion to ensure a proper conservation of one the most important portal of the Norman period in Sicily.

The restoration work has also given the opportunity to investigate and to study the sculptural technique of execution in detail. The very close observation of the bas-reliefs surface showed a different level of execution, attributable to the presence of stoneworkers with distinct artistic abilities in the site work of the Cathedral. In consideration of the great dimension of the portal, it is impossible to appreciate the richness and the sophistication of several details of the stone figures represented on the portal. A suitable 3D documentation is, therefore, crucial for the geometric analysis and interpretive assessment of the monument and for the conservation and valorisation actions.

\section{DATA ACQUISITION}

The close-range photogrammetric survey of the main portal of the Cathedral of Monreale has been planned to obtain a detailed 3D model and a high-resolution ortophoto.

A preliminary study has been realised taking into account several requirements such as the dimension of the portal, the environmental constraints and the level of detail required for the whole portal and for the architectural details. In particular, the survey was aimed to obtain accuracies and resolutions in the order of a few millimetres (about $2 \div 4 \mathrm{~mm}$ ) for the entire portal and sub-millimetre accuracies and resolutions for some architectural details.

The study was aimed to evaluate the most appropriate technical solutions to solve logistical problems and to define the most suitable parameters for image acquisition and data processing.

During this preliminary phase, the height of the portal forced to identify technical devices to define appropriate procedures for the survey of the highest part. Different acquisition strategies were identified: employment of mobile scaffolding, telescopic pole or micro Remotely Piloted Aircraft Systems (RPAS).

The use of a mobile scaffolding is very useful in several cases for Cultural Heritage 3D survey, in particular, for the photogrammetric acquisition of objects that are up to 10-12 meters. This approach allows taking images from very close range both in outdoor or indoor locations (Lo Brutto and Spera, 2012; Echeverría et al., 2017). The use of a mobile scaffolding, even if it ensures optimal conditions for image acquisition, could not be the most simple solution. The set up could take much time, depending on the heights which must be reached; empty spaces are needed to move the scaffolding safely; the management of the scaffolding (assembly, displacement, etc.) needs many people.

An alternative solution could be represented by the use of telescopic pole on which mount a digital camera. This solution, already used in the past (Chiabrando et al. 2010; Martínez et al., 2013), has become increasingly common due to the possibility of using telescopic poles in carbon fibre, very light but also very stable. In addition, the poles can be equipped with a stabilised and remotely adjustable camera system through the use of gimbal similar to those used in RPAS. In this way it is possible to perform acquisition of photogrammetric images with different inclinations of the camera and prevent the pole oscillations, especially when it is used up to the maximum extension that may origin poor quality images. On modern systems, the camera and the gimbal management can be done via notebooks, tablets, smartphones connected via Wi-Fi.

Using RPAS for the survey of monumental or archaeological complex is currently quite frequent (Russo and Manferdini, 2014; Bolognesi et al., 2014; Lo Brutto et al., 2014; Lo Brutto et al., 2017). The RPAS survey is greatly constrained by regulatory restrictions that could limit or, in some cases, prevent the execution of flights in residential areas or settlements, and, in general, where gatherings of people are possible (critical operations). These conditions could, therefore, prevent the use of these systems to carry out the survey of the Cathedral of Monreale since the monument is in the centre of the town of Monreale and it is always visited by many tourists. The Italian Regulation, drafted by Italian Civil Aviation Authority (ENAC) in accordance with European Aviation Safety Agency (EASA) guidelines fixed rules for RPAS. It has, however, defined that all operations with RPAS with operating take-off mass of less than or equal to $0.3 \mathrm{~kg}$, with rotating parts safeguarded against impacts and having maximum speed less than or equal to $60 \mathrm{~km} / \mathrm{h}$ are to be considered non-critical for any operative scenario (ENAC, 2017). These systems could be 
used for photogrammetric applications like the survey of the main portal of the Cathedral of Monreale, but many photogrammetric issues should be studied in detail. In particular, it should be evaluated if the sensors used for image acquisition (usually very small action cameras) can produce satisfactory metric results.

For this first test, we have chosen to use a telescopic pole to perform the image acquisition of the main portal of the Cathedral of Monreale; this system should be the more simple, rapid and low-cost solution. Further tests will be made in next works using a RPAS with operating take-off mass of less than or equal to $0.3 \mathrm{~kg}$ to compare the two different methods of image acquisition.

\subsection{Topographic survey}

In the first step of the work, a topographic survey was performed to determine the coordinates of several ground control points.

A Leica Nova TS60 total station, that allowed recording data with high accuracy, as required for this photogrammetric survey, was used. The Leica Nova TS60 total station has, in fact, an angular accuracy of \pm 0.5 " and a distance accuracy down to sub-millimetre using a prism $( \pm[0.6 \mathrm{~mm}+1 \mathrm{ppm}])$ and in the order of two millimetres on any surface $( \pm[2 \mathrm{~mm}+2 \mathrm{ppm}])$.

It was not possible to put targets on the portal, so natural points distributed along the two pilasters and on the arch, were measured. Distance and angle were measured twice, using an automatic aiming system, to obtain more accurate results.

The measurements were carried out from a benchmark, located in a central position in front of the portal, at a distance of about $20 \mathrm{~m}$ (Figure 6); overall 48 points were measured.

The ground control points coordinates were established in a reference system that had the XY plane parallel to the plane of the portal and the $\mathrm{Z}$ axis facing the outside of the Cathedral (Figure 6).

An accuracy of about $\pm 2 \mathrm{~mm}$ was estimated for the control points applying the error propagation to the formulas for coordinates calculation and considering, as accuracy of the angular and distance measurements, the Leica Nova TS60 values.

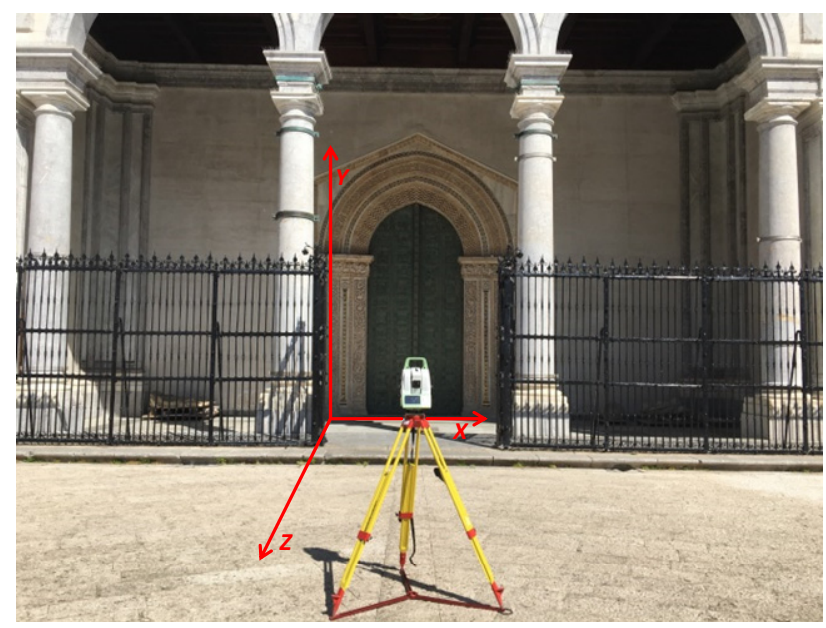

Figure 6. The topographic survey

\subsection{Image acquisition}

Image acquisition was performed with the 3D EYE system, a commercial telescopic pole system developed by MicroGeo s.r.l.. The system is composed of a telescopic pole in carbon fibre with a maximum extension that can reach $13.5 \mathrm{~m}$., a digital camera Sony QX100, an electromechanical stabilisation and remotely adjustable camera support installed on the top of the telescopic pole and a system control via an app installed on an android tablet (Figure 7).

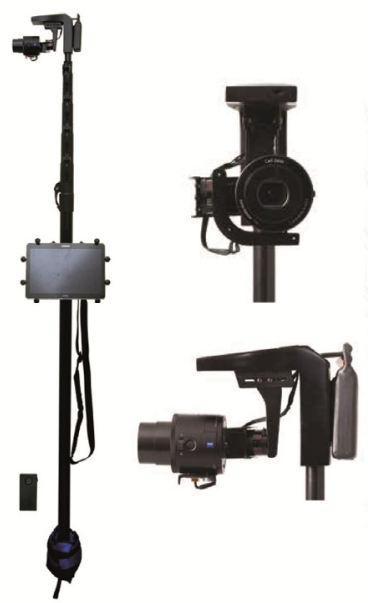

Figure 7. The 3D EYE system

The Sony QX100 camera has a resolution of 5472 pixels x 3648 pixels (approximately 20 megapixels), a pixel size of 2.4 microns and a lens ZEISS ${ }^{\circledR}$ Vario-Sonnar $\mathrm{T}^{*}$ with a focal length range of 10.4-37.1 $\mathrm{mm}$. The camera is produced to be used mainly with a smartphone, but thanks to its small size and especially to its low weight, it could be a very cost-effective solution in all situations where the sensor weight is a key factor (as telescopic pole system or RPAS).

A stereoscopic coverage of several strips, overlapping of $70 \%$ along- and $70 \%$ across-track, was used for image acquisition. These images were acquired from a camera-to-object average distance of about 4.5 meters, using a focal length of $10.4 \mathrm{~mm}$ (Figure 8); a Ground Sample Distance (GSD) of approximately $1.04 \mathrm{~mm}$ was obtained.

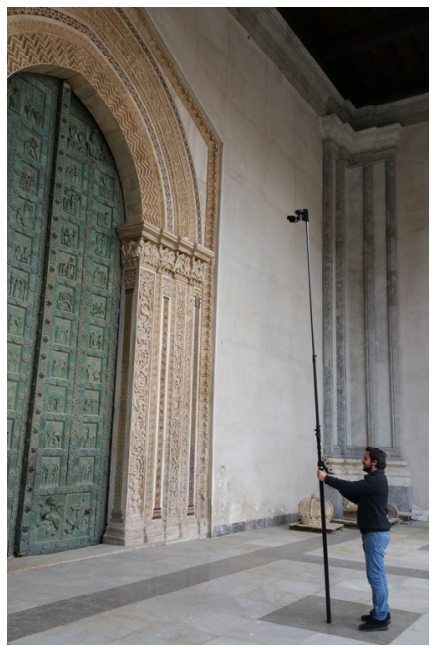

Figure 8. Image acquisition phase

Overall seven strips, from different heights with respect to the ground, were performed; figure 9 shows the different camera height positions.

Some convergent images were also carried out, at the ends of the strips, to strengthen camera network geometry and to get 
more accurate calibration parameters. Moreover, convergent images were also taken from a camera-to-object average distance of about 6 meters and from about 3.5 meters to acquire the inner part of the portal and of the arch (Figure 10). These images are necessary to assure good image coverage for the following 3D reconstruction step. A dataset of 146 images was obtained for the whole portal.

Image acquisition was also carried out for some sculptural elements that should be deeply examined; in particular, one of the capitals on the right, a bas-relief in the right pilaster and a bas-relief in the left pilaster were chosen (Figure 11). These images were acquired from a camera-to-object distance of about 1 meter, achieving a GSD of about $0.23 \mathrm{~mm}$. Almost 90 very close range convergent images were taken ( 36 for the capital, 22 for bas-relief in the right pilaster and 28 for bas-relief in the left pilaster).

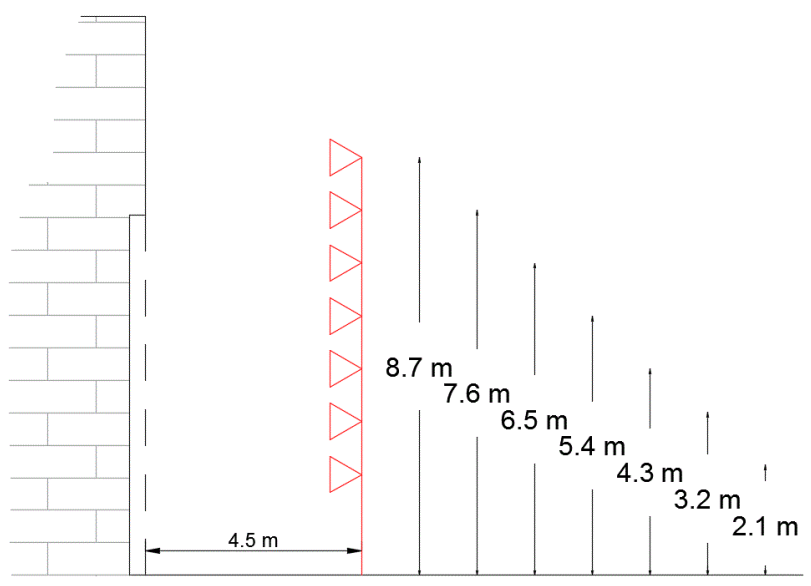

Figure 9. Camera positions at different heights.

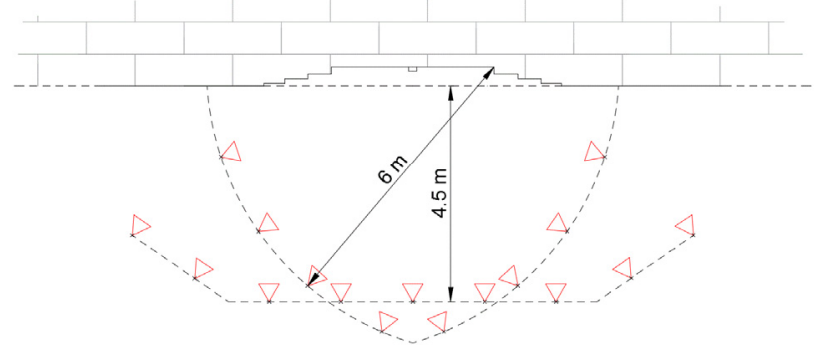

Figure 10. Planimetric camera positions (the camera positions from $3.5 \mathrm{~m}$ are not shown in this scheme)

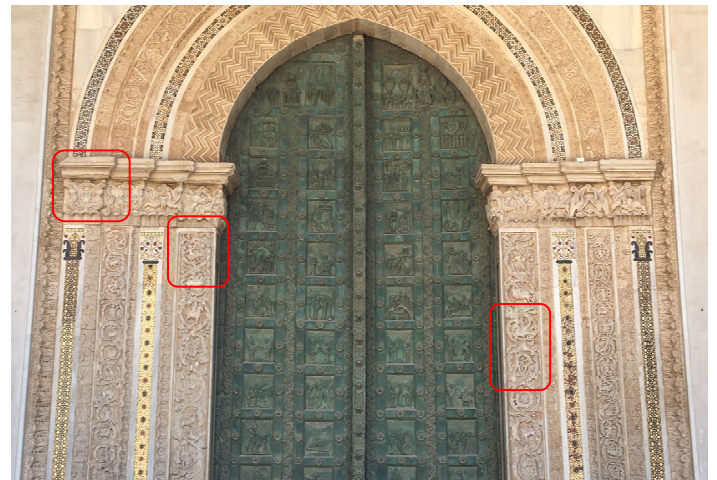

Figure 11. Sculptural elements acquired from a very close range.

\section{DATA PROCESSING}

The image orientation and the 3D reconstruction were carried out with Agisoft Photoscan Pro. All images, both of the whole portal and of the details, were processed together in a single Photoscan Pro project. According to the different camera-toobject distance, several camera calibration parameters were computed during the orientation step.

The coordinates of the points obtained from the topographic measurements were used in part as ground control points, for image orientation, and in part as check points, for the accuracy evaluation (Figure 12)

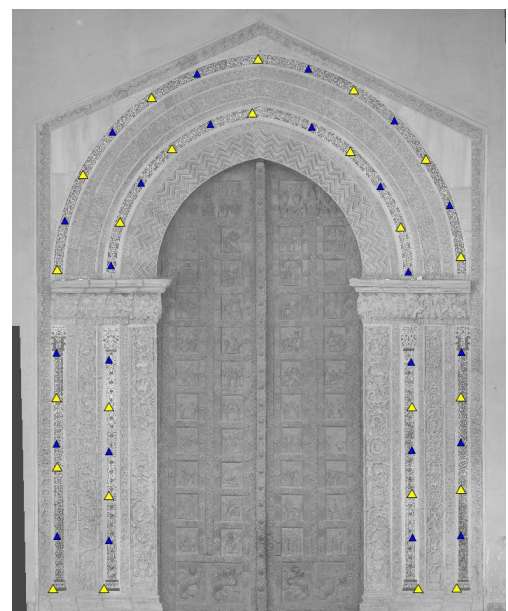

Figure 12. Ground control points (in yellow) and check points (in blue)

Image orientation and 3D reconstruction were performed with typical Photoscan Pro workflow: automatic image orientation by Structure from Motion (SfM), bundle block adjustment to calculate the camera calibration parameters and the exterior orientation parameters, dense image matching to generate $3 \mathrm{D}$ point cloud, 3D reconstructing by polygonal mesh, texture mapping and orthophoto production.

For all camera-to-object distances the principal distance, the coordinates of the principal point, the radial distortion parameters $\left(\mathrm{K}_{1}, \mathrm{~K}_{2}, \mathrm{~K}_{3}\right)$ and the tangential distortion parameters $\left(\mathrm{P}_{1}, \mathrm{P}_{2}\right)$ were computed during the bundle block adjustment. During automatic image orientation by SfM were identified approximately 80.000 tie points; a reprojection error of 1.06 pixels was obtained for image coordinates.

The result of the image orientation shows a root mean square error (RMSE) in XYZ of $1.56 \mathrm{~mm}$ for ground control points and of $1.96 \mathrm{~mm}$ for check points; table 1 reports in detail the result of the image orientation.

During image orientation, some points (both ground control points and check points), that showed anomalous residuals (more than $1 \div 1.5 \mathrm{~cm}$ ), were removed from the process.

Distinct dense point clouds were computed from the images taken from different distances; a dense point cloud of about 24 millions of points and a resolution of about $2.5 \mathrm{~mm}$ was achieved from the images of the whole portal. This dense point cloud was used to obtain a 3D photorealistic model of about 4.8 millions of faces, with a high-quality texture (Figure 13). An ortophoto of the portal with a resolution of $2 \mathrm{~mm}$ was produced too.

The 3D models of the three selected sculptural elements (a capital on the right, a bas-relief in the right pilaster and a basrelief in the left pilaster) were calculated creating three different 
Photoscan Pro projects (one for each sculptural element) from the main Photoscan Pro project. These 3D models have a very impressive resolution, about $0.2 \mathrm{~mm}$, and they allow to appreciate all small details of the sculptures.

It is possible to document and to appreciate the tiny little details of a capital sophisticated sculpture technique with the traces of the original polychromy through it 3D model (Figure 14).

The 3D model of the bas-relief in the right pilaster shows the high level in stoneworking of the artists of the Norman period (Figure 15). The high and deep carving is the peculiar feature of some reliefs of the portal, probably made by specialised craftsmen.

Compared to the right bas-relief, the $3 \mathrm{D}$ model of the left pilaster allows observing some technical differences of the marble carving (Figure 16). In the left part the high quality of the work, highlighted by the presence of small carved details, gives a realistic representation closer to a classicistic style. Instead, the relief on the right part is less detailed and carved than the first one, with a static representation of the figures.

\begin{tabular}{|l|c|c|c|c|c|c|}
\hline & $\begin{array}{c}\text { N. of } \\
\text { points }\end{array}$ & $\begin{array}{c}\mathrm{X} \\
\text { RMSE } \\
{[\mathrm{mm}]}\end{array}$ & $\begin{array}{c}\mathrm{Y} \\
\text { RMSE } \\
{[\mathrm{mm}]}\end{array}$ & $\begin{array}{c}\mathrm{Z} \\
\text { RMSE } \\
{[\mathrm{mm}]}\end{array}$ & $\begin{array}{c}\text { XYZ } \\
\text { RMSE } \\
\text { [mm] }\end{array}$ & $\begin{array}{c}\text { Image } \\
\text { RMSE } \\
\text { [pixel] }\end{array}$ \\
\hline $\begin{array}{l}\text { Ground } \\
\text { Control Points }\end{array}$ & 23 & 0.89 & 1.13 & 0.6 & 1.56 & 0.33 \\
\hline Check Points & 21 & 1.53 & 0.72 & 0.98 & 1.96 & 0.31 \\
\hline
\end{tabular}

Table 1. Results of image orientation

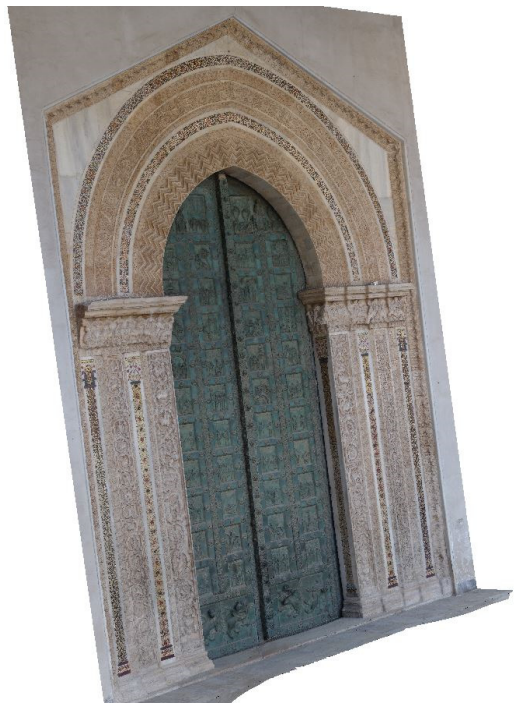

Figure 13. 3D model of the main portal of Cathedral of Monreale

\section{CONCLUSIONS}

At the end of the last restoration work of the main portal of the Cathedral of Monreale, a 3D survey was carried out to document the monumental portal and to analyse some executive specific characteristics of the sculptural decorations. The restoration work has improved the "reading" of this architectural element and has given the opportunity to deeply study the monumental portal.

The 3D survey was carried out by an accurate 3D close-range photogrammetric survey. The image acquisition was planned for different camera-to-object distances and with different

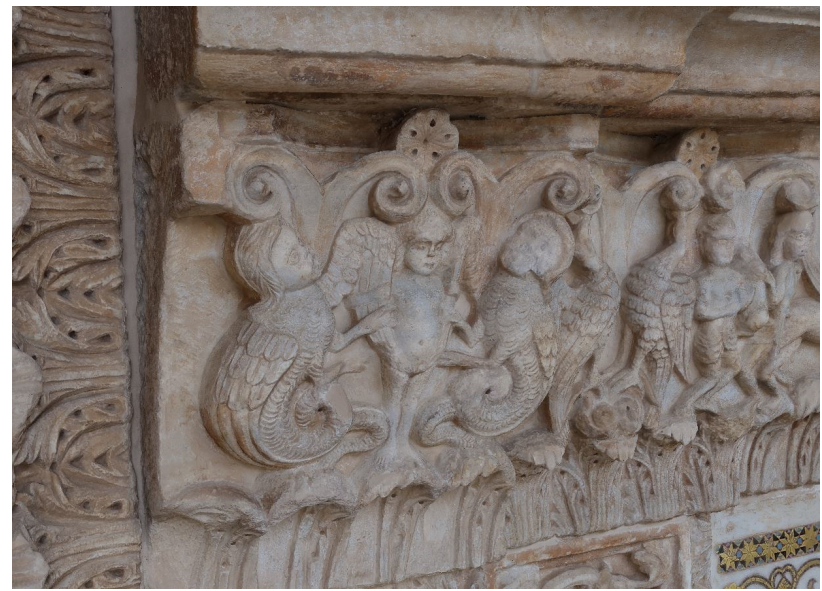

Figure 14. 3D model of the capital

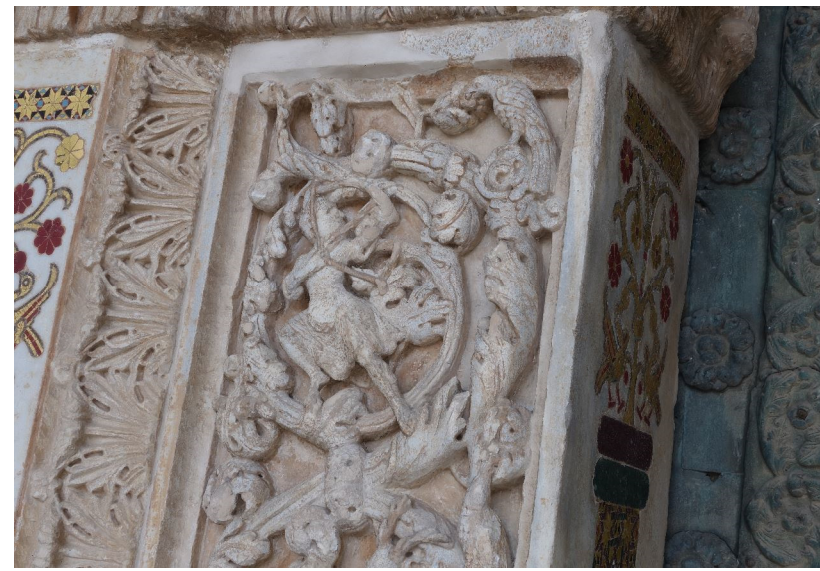

Figure 15. 3D model of the bas-relief in the right pilaster

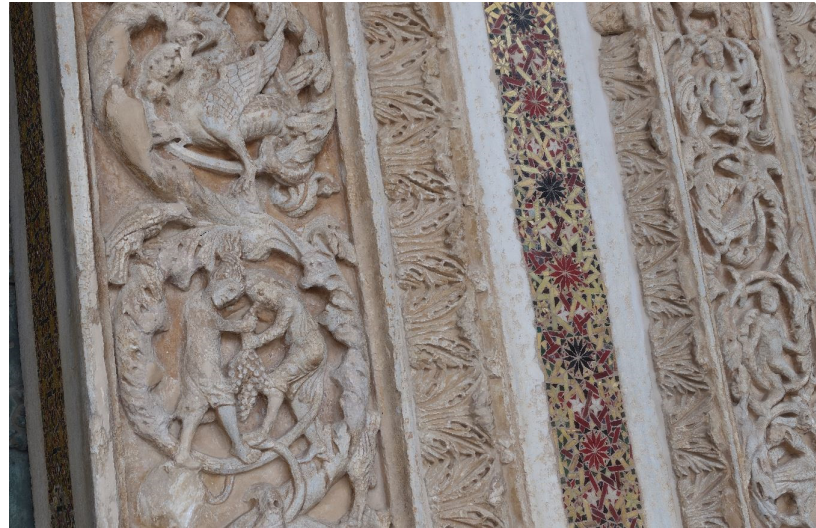

Figure 16. 3D model of the bas-relief in the left pilaster

camera networks. Some images were used for the 3D reconstruction of the whole portal, while other images were used for very detailed 3D reconstruction of some sculptural elements.

The image acquisition was carried out by the telescopic pole system 3D EYE. This approach resulted effective to solve the logistical problems due to the height of the portal and to acquire images in a simple and rapid way.

The metric residuals obtained in image orientation shows accuracy in the order of few millimetres in accordance with the work requirements. 
The level of detail of the 3D models, both for the whole portal and for the sculptural elements, was high and suitable for detailed geometric and interpretative analysis of the architectural features. In addition to the restoration work, the 3D models offer the possibility of a close observation and investigation of such sculptural details and allow to develop further evaluations and comparisons about the techniques of execution that restorers are already investigating. Moreover, the 3D models record the current state of the portal and become an important evidence for the monitoring purpose over time and for valorisation aim too.

\section{ACKNOWLEDGEMENTS}

This work is part of "NEPTIS - ICT-based solutions for augmented fruition and exploration of Cultural Heritage" project founded by Italian Ministry of Education Universities and Research and co-funded by the European Community.

The authors are grateful to Padre Nicola Gaglio of Fabriceria of Cathedral of Monreale that allowed the survey, to Microgeo s.r.l. that loaned the 3 DEye system and to C.G.T. that loaned the Leica Nova TS60 total station.

\section{REFERENCES}

Bolognesi M., Furini A., Russo V., Pellegrinelli A., Russo P., 2014. Accuracy of cultural heritage 3D models by RPAS and terrestrial photogrammetry, In: Int. Arch. Photogramm. Remote Sens. Spatial Inf. Sci., XL-5, pp. 113-119, doi:10.5194/isprsarchives-XL-5-113-2014.

Chiabrando F., Costamagna E., Rinaudo F., Spanò A., 2010. Very close nadiral images: a proposal for quick digging survey. In: Int. Arch. Photogramm. Remote Sens. Spatial Inf. Sci., XXXVIII, Part 5, pp. 155-160.

Echeverría E., Castaño E., Casa F., Celis F. Chias P., 2017. Documental Studio and 3D Recreation of the San Ildefonso's School Facade, Alcala De Henares. In: Int. Arch. Photogramm. Remote Sens. Spatial Inf. Sci., Vol. XLII-2/W3, pp. 283-288, doi:10.5194/isprs-archives-XLII-2-W3-283-2017.

ENAC, 2016. Remotely Piloted Aerial Vehicles Regulation. ENAC Regulations, Issue No. 2 dated 16 July 2015, Revision 2 dated 22 December 2016, http://www.enac.gov.it/Servizio/Info_in_English/Courtesy_tran slations/info-1220929004.html

Fassi F., Achille C., Fregonese L., 2011. Surveying and modelling the main spire of Milan Cathedral using multiple data sources. The Photogrammetric Record, 26(136), pp. 462-487 doi: 10.1111/j.1477-9730.2011.00658.

Fossi G., 2008. Romanesque and Gothic, Sterling, London, p.39.

Kröning W., 1965. Il Duomo di Monreale e l'architettura Normanna, Flaccovio editore, Palermo.

Lo Brutto M., Spera M.G., 2012. Image-based and range-based 3D modelling of archaeological cultural heritage: The telamon of the temple of Olympian Zeus in Agrigento (Italy). In: Int. Arch. Photogramm. Remote Sens. Spatial Inf. Sci., XXXVIII5/W16, pp. 515-522, doi:10.5194/isprsarchives-XXXVIII-5W16-515-2011.
Lo Brutto M., Garraffa A., Meli P., 2014. UAV platforms for cultural heritage survey: first results, In: ISPRS Ann. Photogramm. Remote Sens. Spatial Inf. Sci., Vol. II-5, pp. 227234, doi:10.5194/isprsannals-II-5-227-2014.

Lo Brutto M., Sciortino R., Garraffa A., 2017. RPAS and TLS techniques for archaeological survey: the case study of the archaeological site of Eraclea Minoa (Italy). In: Int. Arch. Photogramm. Remote Sens. Spatial Inf. Sci., XLII-2/W3, pp. 433-438, doi:10.5194/isprs-archives-XLII-2-W3-433-2017.

Martínez S., Ortiz J., Gil M. L., Rego M. T., 2013. Recording complex structures using close range photogrammetry: The Cathedral of Santiago De Compostela. The Photogrammetric Record, 28(144), pp. 375-395, doi:10.1111/phor.12040.

Russo M., Manferdini A. M., 2014. Integration of image and range-based techniques for surveying complex architectures. In: ISPRS Ann. Photogramm. Remote Sens. Spatial Inf. Sci.,Vol. II5, pp. 305-312, doi:10.5194/isprsannals-II-5-305-2014.

White J., 1988, The bronze doors of Bonanus and the development of dramatic narrative, Art History, Vol.11, n.2, pp. $1-10$. 